\title{
Paradoxic effect of Benzodiazepines in geriatric population
}

\begin{abstract}
In daily medical practice there are several special situations against the prescription of benzodiazepines as common in all specialties, however, despite knowledge of their side effects there is controversy and difficulty in the management of geriatric patients. In this way, this is an opportunity through a critical review of the existing literature about the effect of benzodiazepines in the elderly.
\end{abstract}

Keywords: Benzodiazepines, geriatrics, elderly
Volume 3 Issue 3 - 2018

Glauco Valdivieso-Jiménez

Medical Resident of Psychiatry, Hospital Nacional Víctor Larco Herrera, Universidad Nacional Mayor de San Marcos Lima, Perú

Correspondence: Glauco Valdivieso Jiménez, Medical Resident of Psychiatry, Hospital Nacional Víctor Larco Herrera, Universidad Nacional Mayor de San Marcos Lima, Perú, Jr. Arequipa 133, Magdalena del Mar, Lima Email glauco.valdivieso@unmsm.edu.pe

Received: May 01, 2018 | Published: May 08, 2018

\section{Introduction}

Benzodiazepines (BZD), are part of the most known and prescribed pharmacological groups worldwide and nationally since its appearance in the $60 \mathrm{~s}$ after the discovery of barbiturates and their potential uses. It corresponds to a group of drugs that have anxiolytic, hypnotic, anticonvulsant, myorelaxant effects as well as a series of adverse effects.

There are differences between the main BZDs available in our environment due to their pharmacokinetic profile, such as their halflife, potency, time of onset and the duration of action of each one in particular. However, despite its therapeutic virtues, its irrational prescription is a growing reality, leading to its indiscriminate use in general medical practice, with ignorance of its multiple adverse effects and drug interactions, and there are also populations of greater vulnerability to its effects, as in the case of elderly patients. The objective of the following review is to describe the evidence about its adverse effects in geriatric patients.

\section{Methods}

A review of the existing literature was carried out by searching for review articles and clinical research in Medline and Scielo, introducing the keys "benzodiazepines", "geriatrics" and "elderly". The information selected was varied, from 1985 to 2016 . The critical review was made for analysis by the same author.

\section{Rational use of drugs}

The rational use of drugs in Nairobi in 1985 was defined as the prescription of the most appropriate medication for the patient in need, administered at the appropriate doses for the necessary time and providing the patient with the required information about their treatment. Thus, three essential elements are appreciated in their definition for the ideal use of a drug. First, medications are not always required to treat a medical condition; second, prescribing is more than extending a prescription with a business name; and third, it is necessary to involve the patient in his own treatment. ${ }^{1}$
Another important aspect is that prescribing goes much further than writing a prescription, due to the knowledge that the doctor should have of the adverse effects of certain medications according to their previous education, besides that before going to pharmacology, the management is taken into account not pharmacological. After this is considered, the plasma concentration achieved, the minimum and effective dose, patient weight, age, sex, simultaneous intake of other drugs, likely interactions, populations at risk, among other considerations that make prescription an essential art for physicians in all specialties. ${ }^{2}$

Making the patient participate in his therapeutic approach through the information of the procedures, granting him the capacity of choice for a medication after knowing the effects it produces in his organism and answering his doubts, strengthens the doctor-patient relationship and, for therefore, the adherence to treatment, this being a challenge nowadays that we must worry about.

\section{Special situations of the use of BZD}

The BZD as a pharmacological group present potential risks, derived from their pharmacological effect, which depend on the characteristics of the patient, the possible pharmacological interactions and their irrational prescription at inadequate doses or for prolonged periods. $^{3}$

According to this, the attention given to the use of BZD is justified due to the number of adverse effects associated with its use in usual medical practice. Pseudodementia and increased imbalance in the elderly may occur. In isolated cases, paradoxical effects have been reported, such as anxiety, hallucinations and violent actions. In addition, the direct effect of these medications, generates both physical and psychological dependence independently of the age group.,

The hypnotic effect of these drugs diminishes after just a few weeks and the anxiolytic effect disappears in a few months. If the drugs are continued longer than expected, only the adverse effects will be seen, without evidencing any positive effect. ${ }^{4,5}$ 


\section{Pharmacological interactions}

For most BZDs, their microsomal hepatic metabolism is a source of drug interactions. These present frequent interactions both derived from their effect and their metabolism. We must remember that all CNS depressants are potentiated and that the modulation of cytochrome P450 by inducers or inhibitors of the microsomal CYP enzymes is an interaction that we must take into account. The majority of BZDs are metabolized in the liver by oxidation, ie they enter into activity with CYP 3A4 microsomal enzymes, generating active and inactive metabolites, and then by conjugation. Thus, there are drugs very commonly used in our daily practice that interact with BDZ, enhancing or reducing their pharmacological effect, especially with geriatric patients who tend to have other medical conditions.

Oxidation undergoes changes with age, liver failure and with interactions with other drugs, unlike conjugation. Therefore, BZD that only undergo conjugation such as lorazepam and oxacepam are preferred in older adults and patients with liver disease. ${ }^{6}$

\section{Risk of falls}

Accidents rank seventh as a cause of death in older adults. Falls, in turn, are the main cause of accidents in this age group. Although falls often have no fatal consequences, they do affect the health and quality of life of people.

Falls are one of the most important geriatric syndromes due to their high incidence and especially for the repercussions that it will cause on the quality of life of both the elderly and the caregiver. It is reported that one third of people over 65 who live in the community, suffer a fall a year, rising this frequency up to $40 \%$ of the elderly over 75 years. In the institutionalized elderly, given the special characteristics of this group due to their comorbidities and limitations in functionality, the incidence increases up to $50 \%$ annually in the United States. Between 10 and $20 \%$ of falls in institutions produce serious injuries, resulting in 2 to $6 \%$ of fractures in this population. ${ }^{7}$

A meta-analysis showed that the risk of falls in people older than 60 years increases by $41 \%$ in the individuals who take them. The impact of the use of BZD on the hip fracture rate was evaluated in five European countries and in the United States. The greatest use of BZD was in Spain $(22.3 \%$ of the population was treated with BZD in one year) and the lowest in Germany (4.7\%). The risk of hip fractures associated with the use of BZD varied between $1.8 \%$ in Germany and $8.2 \%$ in Spain. The risk of falls was assessed at $40 \%{ }^{8}$

Likewise, with respect to some long-term effects, results of a case-control study conducted in Uruguay also suggest an association between the consumption of BZD and the presence of traumatic hip fracture, the risk being calculated in patients consuming BZD 4.5 times more unlike non-consumers. ${ }^{9}$

In a systematic review in Chile in 2017, it includes studies of authors about elderly patients who had falls and who used significantly more BZD than the control group. Others referred that the consumption of BZD in older adults was associated with an increased risk of fractures due to falls and greater risk of serious fractures. We included studies that showed that older adults who used BZD in the last $24 \mathrm{~h}$ also had a significantly higher risk of falls and serious fractures, among other studies that observed a positive association between BZD consumption and falls in the same population group. ${ }^{10}$

\section{Geriatric syndromes}

In the elderly there are physical changes that affect the pharmacokinetics and can lead to an accumulation of drugs in the body. With age, the volume of distribution of the drug increases, the half-life is prolonged and the sensitivity of the receptors increases.

Between $14-25 \%$ of the elderly receive potentially inappropriate drugs, highlighting the BZD of long half-life. Due to the higher prevalence of chronic diseases, the elderly are subject to receiving long-term therapies with the risk of more drug-related problems. ${ }^{11}$

Problems related to medications have been linked to an increase in the number of hospital admissions and their stay, with greater morbidity and mortality, and they contribute greatly to the hospital cost. The use of BZDs with a long half-life is considered inadequate in the elderly, especially in the elderly, as there is an increase in adverse effects and multiple interactions. Therefore, the elderly constitute a subgroup especially susceptible to adverse effects derived from the BZD, considering the polypharmacy, comorbidities, increased risk of interactions and pharmacokinetic and pharmacodynamic characteristics. ${ }^{11}$

Schumacher et al. ${ }^{12}$ published a study in which they evaluated for 3 months 290 patients older than 65 years admitted to a service of Internal Medicine in Switzerland, noting that most of these received for a prolonged period during their internment benzodiazepines as lorazepam and oxazepam, in addition to drugs Z. This increased the risk of adverse effects related to the elderly. ${ }^{12}$

Oscanoa $^{13}$ in a study conducted in Lima-Perú, included 500 hospitalized geriatric patients, evidencing that in these the prevalence of prescribing at least one medication inappropriate at admission, during hospitalization and discharge was $12.4 \%, 3.4 \%$ and $2.1 \%$, respectively, with the most prescribed drugs being diazepam, digoxin, iron, chlorphenamine and amitriptyline. Finally, it concludes that the factors related to inadequate prescription and that increase the risk and complication of additional medical syndromes were polypharmacy, polypathology and chronic pain. ${ }^{13}$

\section{Cognitive deterioration}

To date there is regular information about the effect on the cognitive functions of the BZD, especially in certain aspects such as attention and memory. However, what is not known is to what extent the chronic or prolonged use of BZD produces global cognitive impairment or dementia. Some studies show an increase in risk with prolonged use, but the information in general terms is contradictory. Special interest in the scientific community is the risk of dementia, especially when some initial symptoms of dementia, anxiety, insomnia and depressive syndrome are treated many times with BZD. There are three major studies of interest that addressed this problem, two of which showed a risk of dementia associated with prolonged use of BZD and another not.

A prospective study conducted in France that included more than 1000 dementia-free participants with a 15 -year follow-up found a significant $50 \%$ risk of dementia in new BZD users. Anyway, this study has several limitations, since only 95 participants were strictly new users of BZD, there were many losses in the follow-up and other confounding factors such as anxiety and sleep disorder whose symptoms may overlap were not contemplated. its beginnings with the demential syndrome in initial stages..$^{14}$ 
Gallacher et al. ${ }^{15}$ in conducted a case-control study that evaluated 2 . the risk of Alzheimer's disease among chronic BZD users, finding significant increased risk among BZD users. ${ }^{15}$

In the United States, in a prospective study conducted by Gray in 2016, more than 3000 patients were included, but they did not show an increase in the incidence of cognitive impairment or dementia when exposed to high doses of BZD, but in the presence of lower doses, without However, the evidence from this study remained uncertain. ${ }^{16}$

On the other hand, there have been systematic reviews that during their execution have been faced with the barrier of methodological biases in most studies that aimed to study this problem, leading to 6 . conclude that the evidence of cognitive damage that the BZD produces will still remain in the uncertainty for which the doctor of today will learn to take into account these observations and avoid producing more damage to the over prescription of BZD. ${ }^{17}$

\section{Dependence on BZD}

As we have reviewed, the chronic consumption of BZD is a huge health problem, causing major adverse effects in at-risk populations and this is a trend in the elderly. In the United Kingdom, the Drug Safety Committee recommends using BZD only for the symptomatic and short-term relief of anxiety or insomnia, approximately 2 to 4 weeks. In France, where the consumption of BDZ is among the highest in Europe, the High Health Authority promoted a campaign with the aim of reducing prolonged consumption among patients over 65 years of age, training doctors in general on criteria and plans of dose reduction to finally remove it. ${ }^{18}$

It refers to a chronic consumption, the uninterrupted administration after 3 months, because before this problem appears the so-called dependence to BZD. This is due to the physiological adaptation of the organism that appears after prolonged use so that, when interrupting its administration, it can produce a significant discomfort that induces the individual to maintain consumption. This adaptation is the biological basis for tolerance to occur and the appearance of withdrawal or withdrawal symptoms when stopping its use. ${ }^{19}$

\section{Conclusion}

Inappropriate use of BZD is common in most physicians today. The knowledge learned about its adverse effects should be kept in mind at all times because in geriatric patients there is a greater risk of drug interaction, risk of falls and fractures, greater cognitive deterioration and risk of dependence. It is time to become aware of its irrational use and the negligent effects that could be caused independently of the specialty of the attending physician.

\section{Acknowledgements}

None.

\section{Conflict of interest}

The author has no conflict of interest to report.

\section{References}

1. Conference of Experts on the Rational Use of Drugs. The rational use of drugs. Report of the conference of experts. World Health Organization: Geneva. 1987.
Figueras A. Dificultades para el uso racional de medicamentos. Revista Peruana de Medicina Experimental y Salud Pública. 2009;26(4):549-552.

3. Losada CL. Hacemos un uso adecuado de las benzodiacepinas? Conocimientos prácticos para atención primaria. Rev Med Gral. 2008;112:780-7.

4. Jørgensen VRK, Toft BS, Fogh MVS. Reducir el uso de benzodiazepinas y ciclopirrolonas en práctica clínica. Pharmacy Practice. 2006;4(2):74-78.

5. Ashton $\mathrm{CH}$. Guidelines for the rational use of benzodiazepines. When and what to use. Drugs. 1994;48(1):25-40.

Danza A, Cristiani F, Tamosiunas G. Riesgos asociados al uso de benzodiacepinas. Arch Med Interna. 2009;31(4):103-7.

7. Woolcott JC, Richarson KJ, Wiens MO, et al. Metaanalysis of the impact of 9 medication classes on falls in elderly persons. Arch Intern Med. 2009;169(21):1952-60.

8. Khong TP, de Vries F, Goldenberg JSB, et al. Potencial impact of benzodiazepine use on the rate of hip fractures in five large european countries and the United States. Calcif Tissue Int. 2012;91:24-31

9. Danza A, Rodríguez BM, López PM, et al. Benzodiacepinas y fractura de cadera: estudio de casos y controles. Rev Méd Urug. 2015;31(2):119-126.

10. Gómez S, León T, Macuer M, et al. Uso de benzodiazepinas en adultos mayores en América Latina. Rev Med Chile. 2017;145(3):351-359.

11. De Vries OJ, Peeters G, Elders P, et al. The elimination half-life of benzodiazepines and fall risk: two prospective observational studies. Age and Ageing. 2013;42:764-70.

12. Schumacher L, Dobrinas M, Tagan D, et al. Prescription of sedative drugs during hospital stay: a swiss prospective study. Drugs Real World Outcomes. 2017;4(4):225-234.

13. Oscanoa T. Uso inadecuado de medicamentos en adultos mayores. An Fac Med Lima. 2005;66(1).

14. Billioti GS, Begaud B, Bazin F, et al. Benzodiazepine use and risk of dementia: prospective population based study. BMJ. 2012;345:e6231.

15. Gallacher J, Elwood P, Pickering J, et al. Benzodiazepine use and risk of dementia: evidence from the Caerphilly Prospective Study (CaPS). $J$ Epidemiol Community Health. 2012;66(10):869-73.

16. Gray SL, Dublin S, Yu O, et al. Benzodiazepine use and risk of incident dementia or cognitive decline: prospective population based study. $B M J$. 2016;352:i90.

17. Defrancesco M, Marksteiner J, Fleischhacker WW, et al. Use of benzodiazepines in alzheimer's disease: A Systematic Review of Literature. Int J Neuropsychopharmacol. 2015;19;18(10):pyv055.

18. http://www.mhra.gov.uk/ConferencesLearningCentre/ LearningCentre/Medicineslearningmodules/Reducingmedicinerisk/ Benzodiazepineslearning odule/CON234573

19. Busto U, Sellers EM, Naranjo CA, et al. Withdrawal reaction after longterm therapeutic use of benzodiazepines. N Engl J Med. 1986;315:654659 . 